\title{
Níveis de Concentrado na Dieta de Novilhos F1 Limousin x Nelore: Consumo, Conversão Alimentar e Ganho de Peso1
}

\section{Antonio Gesualdi Júnior ${ }^{2}$, Mário Fonseca Paulino ${ }^{3}$, Sebastião de Campos Valadares Filho ${ }^{3}$, José Fernando Coelho da Silva ${ }^{4}$, Cristina Matos Veloso ${ }^{2}$, Paulo Roberto Cecon ${ }^{5}$}

\begin{abstract}
RESUMO - Utilizaram-se 45 bovinos F1 Limousin x Nelore, inteiros, com, em média, 14 meses de idade e peso vivo inicial de $330 \mathrm{~kg}$, para avaliar os efeitos de diferentes níveis de concentrado na matéria seca $(25,0 ; 37,5 ; 50,0 ; 62,5$; e 75,0\%) e dois métodos de balanceamentos de rações (o primeiro, tendendo a ser isoprotéico e o segundo, variando proteína com energia) sobre os consumos de matéria seca (CMS) e fibra em detergente neutro (FDN), conversão alimentar (CA), ganhos diários de peso vivo (GMDPV), corpo vazio (GMDPVZ) e carcaça (GCAR). Cinco animais foram abatidos no início do experimento, como referência, para estimar o peso corporal vazio inicial dos animais que permaneceram no confinamento. Os animais receberam alimentação à vontade até atingirem o peso de abate preestabelecido de $500 \mathrm{~kg}$. Foi utilizado o feno de capim-coastcross como fonte de volumoso na dieta. O delineamento foi o inteiramente casualizado, em esquema fatorial 2 x 5, com quatro repetições. As formas de balanceamento resultaram em igual desempenho dos animais. Os consumos de MS responderam de maneira quadrática, estimando-se os máximos de 8,04 kg MS, 1,99\% PV e 89,22 g MS/kg 0,75 para os níveis de 41,42; 36,71; e 37,96\% de concentrado, respectivamente. Conversão alimentar, consumo de FDN e dias de confinamento decresceram e o GMDPVZ cresceu linearmente, com o aumento dos níveis de concentrado na ração. Os GMDPV e GCAR apresentaram resposta quadrática, com máximos de 1,16 e $0,81 \mathrm{~kg}$ para 61,11 e 64,47\% de concentrado, respectivamente.
\end{abstract}

Palavras-chave: desempenho, F1 Limousin x Nelore, nível de concentrado

\section{Concentrate Levels in the Diet for Crossbreed Limousin x Nellore Bulls: Intake, Feed:Gain Ratio and Weight Gain}

\begin{abstract}
Forty five crossbreed F1 Limousin x Nellore young bulls, averaging 14 months of age and initial $330 \mathrm{~kg}$ LW, were used to evaluate the effects of different concentrate levels (25.0, 37.5, 50.0, 62.5 and 75.0\% as DM basis) and two diet balance methods (one, almost isoprotein and the second, changing protein as energy of the diet change) on the intakes of dry matter (DMI) and neutral detergent fiber (NDFI), feed: gain ratio (FG), daily gains of live weight (ALWDG) empty body weight (EBWDG) and carcass weight (CARG). Five animals were slaughtered in the beginning of the experiment as reference, to estimate the initial empty body weight of animals that remained in feedlot. The animals were full fed up to the slaughter weight of $500 \mathrm{~kg}$. The coast-cross grass hay was used as forage source in the diet. A completely randomised design in a 2 x 5 factorial arrangement, with four replicates was used. The two diet balance methods resulted on equal animal performances. The dry matter intake showed a quadratic response, and a maximum values of $8.04 \mathrm{~kg} \mathrm{DM}, 1.99 \% \mathrm{LW}$, and $89.22 \mathrm{~g} \mathrm{DM} / \mathrm{kg}^{0.75}$ for the concentrate levels of 41.42, 36.71, and 37.96\%, respectively were estimated. The feed: gain ratio, NDFI and days in fed decreased and ALWDG linearly increased as the concentrate levels in the diet increase. The ALWDG and CARG showed quadratic response, with maximum of 1.16 and 0.81 for 61.11 and $64,47 \%$ of concentrate level in the diet.
\end{abstract}

Key Words: performance, F1 Limousin x Nellore, concentrate level

\section{Introdução}

De acordo com MERTENS (1994), o desempenho animal é função direta do consumo de matéria seca digestível; nesse contexto, 60 a $90 \%$ decorrem de variação do consumo e10 a 40\%, de flutuações na digestibilidade. MERTENS (1992) afirmou que a ingestão de alimentos é função do animal (peso vivo e sua variação, nível de produção, estádio de lactação, estado fisiológico e tamanho), do alimento (fibra, volume, capacidade de enchimento, densidade energética e necessidade de mastigação) e das condições de alimentação (disponibilidade de alimento, espaço no cocho, tempo de acesso ao alimento, frequência de alimentação etc), além das condições climáticas.

\footnotetext{
${ }^{1}$ Parte da Tese de Mestrado em Zootecnia, apresentada pelo primeiro autor à UFV, financiada pela FAPEMIG.

${ }^{2}$ Aluno de Doutorado em Zootecnia, Departamento de Zootecnia, UFV - Viçosa, MG. E.mail: anaton@vicosa.com.br

${ }^{3}$ Professor do Departamento de Zootecnia, UFV - Viçosa, MG. Bolsista do CNPq.

${ }^{4}$ Professor da UENF - Campos, RJ.

${ }^{5}$ Professor do Departamento de Matemática, UFV - Viçosa, MG.
} 
De acordo com o NATIONAL RESEARCH COUNCIL - NRC (1987), o consumo de dietas com alto teor de fibra é controlado por fatores físicos, como enchimento ruminal e taxa de passagem da digesta, ao passo que dietas com altos teores de concentrado (alta densidade energética) têm seu consumo controlado pela demanda energética do animal e por fatores metabólicos.

Para se estimar o consumo potencial de um alimento, este deve ser separado nas frações que limitam o consumo, devido à sua capacidade de "enchimento", associado à densidade específica daquelas que limitam o consumo, em virtude da densidade energética.

CARVALHO et al. (1996), trabalhando com animais Nelore e cinco níveis de concentrado (20,0; 32,$5 ; 45,0 ; 57,5 ;$ e 70,0\%), utilizando como volumoso o feno de capim-elefante (Penissetum purpureum Schum.), concluíram que o consumo de fibra em detergente neutro (FDN) reduziu linearmente com maiores níveis de concentrado na dieta. Por outro lado, RODRIGUEZ et al. (1996), ao fornecerem rações contendo 12,$5 ; 25,0 ; 37,5$; e $50 \%$ de concentrado e feno de capim-brachiária (Brachiaria decumbens Stapf.), encontraram ingestão constante de FDN, apesar da elevação do percentual de concentrado nas rações.

No Brasil, as rações utilizadas para gado de corte, na maioria das vezes, são compostas basicamente de volumoso, sendo a limitação da ingestão de energia o fator preponderante para o baixo desempenho dos animais em confinamento.

OLIVEIRA et al. (1998), avaliando níveis crescentes de concentrado $(25 ; 37,5 ; 50 ; 62,5 ;$ e $75 \%)$ na dieta de bovinos Nelore em confinamento, encontraram resposta quadrática para consumo de matéria seca, expresso em \% PV, sendo o maior valor alcançado com o nível de $58,47 \%$. De forma semelhante, TIBO et al. (1997), utilizando os mesmos níveis de concentrado, encontraram ingestão máxima com o nível de $69,92 \%$.

CARVALHO et al. (1996), BURGER et al. (1998) e SIGNORETTI et al. (1998) não verificaram diferenças no consumo de matéria seca, ao fornecerem dietas com níveis crescentes de concentrado em substituição ao feno. Por outro lado, FERREIRA (1997) e LADEIRA et al. (1998) relataram resposta linear para consumo, fornecendo rações com níveis de até $75 \%$ de concentrado e fenos dos capins braquiária e coastcross, em proporções iguais. Isso mostra que maiores níveis de concentrado na dieta podem não apresentar o resultado esperado. Em alguns casos, ocorre redução do consumo, como observado por EUCLIDES FILHO et al. (1997), fornecendo dietas com 0,40 e $60 \%$ de concentrado e feno de capim Tanzania-1, e GONÇALVES et al. (1991), utilizando proporções de 20 e $60 \%$ de concentrado em relação ao feno de capim-gordura (Melinis minutiflora, Beauv.).

Embora resultados experimentais mostrem que o ganho de peso médio diário é maior quando se utilizam rações com maior porcentagem de concentrado (BARTLE et al., 1994; FERREIRA, 1997; e OLIVEIRA et al., 1998), a resposta animal à adição de concentrado, entretanto, tende a ser quadrática e não-linear (VEIRA et al., 1994; ARAÚJO et al., 1997; e TIBO et al., 1997). Assim, o nível ótimo, considerando-se o desempenho animal e a eficiência econômica do sistema, é variável e tem como fatores determinantes sexo, raça e idade do animal, qualidade do volumoso e concentrado, entre outros.

Diversos resultados têm indicado diferenças na taxa de conversão alimentar, a partir de variações no teor energético da ração (EUCLIDES FILHO et al., 1996; FEIJÓ et al., 1996; FERREIRA, 1997; e OLIVEIRA et al., 1998). Segundo NEUMANN (1977), maior densidade energética resulta em maior ingestão de energia; por conseguinte, menos alimento é requerido para o ganho de peso.

A ingestão de proteína pode influir no consumo de matéria seca e, conseqüentemente, no desempenho animal. Segundo PETIT et al. (1994), a suplementação protéica de dietas à base de silagens resultou em aumento no consumo de matéria seca e ganho médio diário de peso vivo, além de redução na conversão alimentar, em comparação à suplementação exclusiva de energia. Resultados semelhantes foram relatados por VEIRA et al. (1994). Por outro lado, SALOMONI et al. (1980), estudando níveis crescentes de energia na terminação de novilhos azebuados, recebendo rações isoprotéicas, não encontraram diferenças no ganho médio diário de peso vivo. ALVES et al. (1998), também, não relataram diferenças nos consumos de matéria seca, na conversão alimentar e no ganho médio diário de peso vivo, ao fornecerem duas dietas com silagem de milho a novilhos zebu e mestiços, mesmo verificando diferenças na ingestão de proteína bruta da ordem de $0,270 \mathrm{~kg}$ entre as dietas.

Vários estudos realizados no Brasil têm mostrado diferenças no consumo de alimento, no ganho de peso vivo e na conversão alimentar entre Bos taurus, Bos indicus e seus mestiços (GALVÃO et al., 1991; GONÇALVES et al., 1991; e EUCLIDES FILHO et al., 1996). 
1460 Rev. bras. zootec.

O consumo de MS, expresso em gMS/kg0,75, foi, em média, 20\% superior para taurinos em relação a zebuínos, sendo que os mestiços apresentaram valores intermediários (GONÇALVES et al., 1991). Por outro lado, GALVÃO et al. (1991) constataram que animais F1 Marchigiana $\mathrm{x}$ Nelore apresentaram maiores consumos que F1 Limousin x Nelore e Nelore, não havendo diferenças entre ambos os grupos.

Com o objetivo de avaliar dietas com cinco níveis de concentrado e duas formas de balanceamento de rações - NRC (1984, 1996) - sobre os consumos de matéria seca (MS) e fibra em detergente neutro, a conversão alimentar, o ganho de peso de corpo vazio e de carcaça e os ganhos médios diários de peso vivo, foi desenvolvido este trabalho com animais F1 Limousin x Nelore, não-castrados.

\section{Material e Métodos}

O experimento foi conduzido no Laboratório de Animais do Departamento de Zootecnia da Universidade Federal de Viçosa, Viçosa, Minas Gerais.

Foram utilizados 45 novilhos F1 Limousin x Nelore, não-castrados, com peso vivo médio de $330 \mathrm{~kg}$. Os animais foram mantidos em regime de confinamento, em baias individuais de $30 \mathrm{~m}^{2}$, sendo $8 \mathrm{~m}^{2}$ de área coberta, providas de comedouro e bebedouro de concreto. Os animais passaram por um período de adaptação de 45 dias, durante o qual todos foram identificados e tratados contra ecto e endoparasitas, recebendo o mesmo manejo alimentar.

Cinco novilhos foram abatidos após o período de adaptação (grupo referência), servindo de referência nos estudos subsequientes. Os 40 animais restantes foram distribuídos em 10 tratamentos (cinco níveis de concentrado x duas formas de balanceamento protéico), divididos, aleatoriamente, em cinco grupos de oito animais cada um e recebendo as seguintes rações: R25 - ração com relação volumoso:concentrado de 75:25; R37,5 - ração com relação volumoso:concentrado de 62,5:37,5; R50 - ração com relação volumoso: concentrado de 50:50; R62,5 - ração com relação volumoso:concentrado de 37,5:62,5; e R75 - ração com relação volumoso:concentrado de 25:75.

Em cada grupo, quatro animais foram alimentados com rações formuladas para serem isoprotéicas, com, aproximadamente, $12 \%$ PB na MS, de acordo com o NRC (1984), e quatro animais foram alimentados com rações formuladas de acordo com o NRC (1996), nível dois. As rações formuladas por este último sistema não eram isoprotéicas, sendo balanceadas de acordo com o proposto pelo CORNELL NET CARBOHYDRATE AND PROTEIN SYSTEM (CNCPS).

Os teores de matéria seca, matéria orgânica, proteína bruta, extrato etéreo, carboidratos totais, fibra em detergente neutro e carboidratos não-estruturais das rações experimentais estão expressos na Tabela 1 .

$\mathrm{O}$ alimento foi fornecido uma vez ao dia, ad libitum, de forma a manter as sobras em torno de 5 a $10 \%$ do oferecido.

Utilizou-se o feno de capim-coastcross (Cynodon dactylon) como volumoso.

Foi efetuado o registro do alimento consumido, amostrando-se os alimentos fornecidos e as sobras.

A cada 28 dias, foi feita uma amostra composta das sobras coletadas semanalmente e moídas em moinho tipo "Willey", com peneira de 30 mesh, para a análise de matéria seca, que foi efetuada conforme descrito por SILVA (1990).

Os animais foram pesados no início do experimento e, subseqüentemente, a cada 28 dias.

$\mathrm{O}$ abate dos animais do grupo experimental ocorreu quando atingiram $500 \mathrm{~kg}$ de peso vivo e, à medida que se aproximavam deste peso, eram pesados a intervalos menores. Os animais foram abatidos por meio de concussão cerebral, após jejum de 16 horas.

Por ocasião do abate, os animais foram pesados e obtidas amostras de couro, pés e cabeça, bem como de rúmen-retículo, omaso, abomaso, intestino delgado, intestino grosso vazio, gordura interna, coração, fígado, rins, baço, pulmões, língua, sangue, mesentério, cauda, além de esôfago, traquéia e aparelho reprodutor (pesados em conjunto).

O peso do corpo vazio (PCVZ) dos animais foi obtido pela soma dos pesos de carcaça, sangue, cabeça, couro, pés, cauda, vísceras e órgãos. A relação obtida entre o PCVZ e o peso vivo (PV) dos animais referência foi utilizada para estimar o PCVZ inicial dos animais dos tratamentos.

O delineamento experimental adotado foi o inteiramente casualizado, em esquema fatorial 5 x 2 , com quatro repetições, sendo cinco níveis de concentrado e duas formas de balanceamento protéico (uma tendendo a ser isoprotéica com, aproximadamente, $12 \%$ $\mathrm{PB}$ e outra variando proteína com energia). Os dados foram avaliados por meio de análises de variância e regressão, utilizando-se o Sistema de Análises Estatísticas e Genéticas - SAEG (UNIVERSIDADE FEDERAL DE VIÇOSA - UFV, 1995). Os coeficientes de regressão foram comparados pelo teste " $t$ ", a 1 e 5\%, e, no caso da variável consumo de matéria seca, expressa em kg/dia, a $10 \%$ de probabilidade. 
GESUALDI JR. et al.

Tabela 1 - Teores de matéria seca (MS), matéria orgânica (MO), proteína bruta (PB), extrato etéreo (EE), carboidratos totais $(\mathrm{CHO})$, fibra em detergente neutro (FDN) e carboidratos não-estruturais (CNE) das rações experimentais

Table 1 - Dry matter (DM\%), organic matter (OM), crude protein (CP), ether extract (EE), total carbohydrates (CHE), neutral detergent fiber (NDF) and non structural carbohydrates (NEC) levels, in the experimental diets

\begin{tabular}{|c|c|c|c|c|c|c|c|c|c|c|}
\hline \multirow{4}{*}{$\begin{array}{l}\text { Nutrientes } \\
\text { Nutrients }\end{array}$} & \multicolumn{10}{|c|}{$\begin{array}{l}\text { Níveis de concentrado (\%) } \\
\text { Concentrate levels }\end{array}$} \\
\hline & \multicolumn{2}{|c|}{25} & \multicolumn{2}{|c|}{32,5} & \multicolumn{2}{|c|}{50} & \multicolumn{2}{|c|}{67,5} & \multicolumn{2}{|c|}{75} \\
\hline & \multicolumn{10}{|c|}{$\begin{array}{l}\text { Balanceamento protéico* } \\
\text { Protein counter balancing }\end{array}$} \\
\hline & 1 & 2 & 1 & 2 & 1 & 2 & 1 & 2 & 1 & 2 \\
\hline $\begin{array}{l}\mathrm{MS} \% \\
D M \%\end{array}$ & 83,88 & 82,75 & 94,56 & 83,43 & 85,63 & 84,10 & 87,30 & 84,78 & 87,84 & 85,51 \\
\hline $\mathrm{MO}^{1}$ & 94,99 & 94,89 & 95,26 & 95,24 & 95,68 & 95,57 & 96,27 & 95,92 & 96,30 & 96,28 \\
\hline $\begin{array}{l}\mathrm{PB}^{1} \\
C P^{1}\end{array}$ & 10,61 & 10,62 & 10,55 & 11,81 & 10,98 & 12,80 & 11,25 & 14,39 & 12,27 & 15,49 \\
\hline $\mathrm{EE}^{1}$ & 1,58 & 1,91 & 1,88 & 2,22 & 2,26 & 2,58 & 2,42 & 2,90 & 2,61 & 3,26 \\
\hline $\begin{array}{l}\mathrm{CHO}^{1} \\
\mathrm{CHE}^{1}\end{array}$ & 82,80 & 82,36 & 82,81 & 81,20 & 82,44 & 80,19 & 82,60 & 78,62 & 81,83 & 77,52 \\
\hline $\begin{array}{l}\mathrm{FDN}^{1} \\
N D F^{1}\end{array}$ & 62,78 & 62,95 & 54,62 & 57,28 & 46,35 & 45,69 & 37,92 & 36,88 & 28,99 & 28,63 \\
\hline $\begin{array}{l}\mathrm{CNE}^{1} \\
N E C^{l}\end{array}$ & 17,46 & 19,40 & 25,06 & 26,89 & 32,32 & 34,49 & 37,16 & 41,73 & 46,54 & 48,88 \\
\hline
\end{tabular}

1 Porcentagem na MS (DM percentage).

* 1 - Isoprotéico (NRC, 1984) (1 - Non variable protein [NRC, 1984]).

2 - Proteína variada (NRC, 1996) (2 - Variable protein [NRC, 1996]).

O modelo estatístico utilizado foi:

$$
\mathrm{Y}_{\mathrm{ijk}}=\mathrm{m}+\mathrm{C}_{\mathrm{i}}+\mathrm{F}_{\mathrm{j}}+\mathrm{CF}_{\mathrm{ij}}+\mathrm{e}_{\mathrm{ijk}}
$$

em que Yijk é a observação referente ao animal k, recebendo o nível de concentrado $\mathrm{i}$, sob a forma de balanceamento $\mathrm{j} ; \mathrm{m}$, a média geral; $\mathrm{C}_{\mathrm{i}}$, o efeito do nível de concentrado $\mathrm{i} ; \mathrm{F}_{\mathrm{j}}$, o efeito da forma de balanceamento $\mathrm{j} ; \mathrm{CF}_{\mathrm{ij}}$, o efeito da interação entre o nível de concentrado $\mathrm{i}$ e a forma de balanceamento $\mathrm{j}$; e $e_{i j k}$, o erro experimental.

\section{Resultados e Discussão}

As análises de variância não evidenciaram a existência de interação de níveis de concentrado e formas de balanceamento das rações, para qualquer variável estudada; além disso, as formas de balanceamento apresentaram resultados semelhantes, a 5\%. Assim, os dados foram agrupados e as análises, realizadas em função dos níveis de concentrado.

As médias e as equações ajustadas, com os respectivos coeficientes de determinação e variação, dos consumos de matéria seca, em kg/dia, em relação ao peso vivo e ao peso metabólico, dos consumos de FDN, em relação ao peso vivo, da conversão alimentar e dos dias gastos no confinamento, em função dos níveis de concentrado na ração, são apresentados na Tabela 2.
O consumo de matéria seca, em kg/dia, apresentou resposta quadrática $(\mathrm{P}<0,10)$ aos níveis de concentrado (Tabela 2 e Figura 1), estimando-se o consumo máximo de 8,04 kg MS/dia, com 41,42\% de concen-

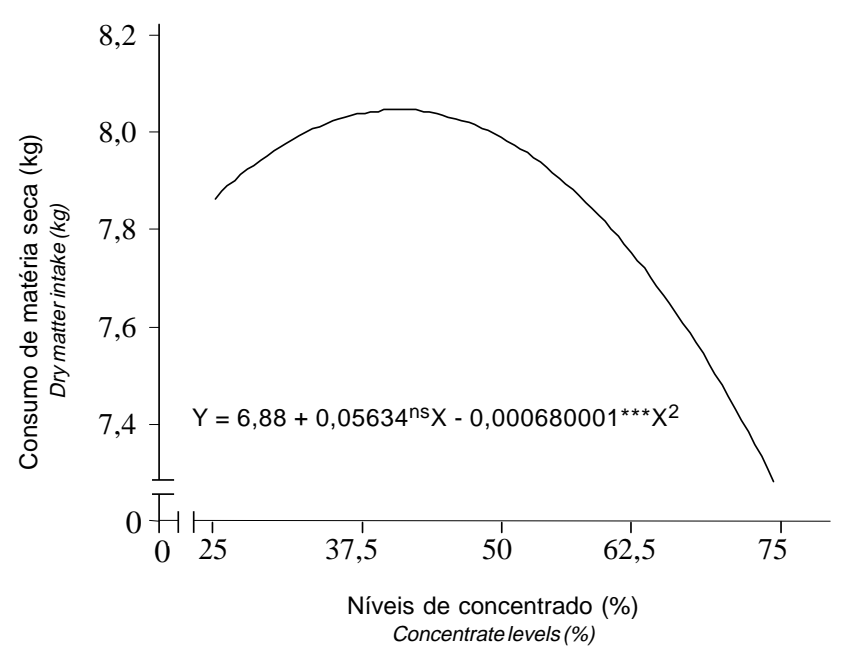

Figura 1 - Estimativa do consumo diário de matéria seca (CMS), expresso em kg, em função dos níveis de concentrado nas rações (X), expressos em porcentagem.

Figure 1 - Estimates of daily dry matter intake (DMI), in $\mathrm{kg}$, in function of concentrate levels, expressed in percentage. 
1462 Rev. bras. zootec.

Tabela 2 - Médias e equações de regressão (ER), com os coeficientes de determinação e variação, para os consumos de matéria seca (kgMS/dia), em relação aos pesos vivo (\%PV) e metabólico ( $\left.\mathrm{g} \mathrm{MS} / \mathrm{kg}^{0,75}\right)$, consumo de FDN em relação ao peso vivo (CFDN), conversão alimentar expressa em $\mathrm{kg}$ de MS consumida/kg de peso vivo (CA) e dias de confinamento (DC), em função dos níveis de concentrado nas rações (X), \%

Table 2 - Means and fitted regressions, with the coefficients of variation and determination, for dry matter intake (DMI), as percentage of live weight $(\% \mathrm{LW})$ and metabolic weight $\left(\mathrm{gDM} / \mathrm{kg}^{0.75}\right), \mathrm{NDF}$ intake as percentage of live weight (NDFI), feed:gain ratio (F/G), and days fed (DF), in function of concentrate levels in the diets, (\%)

\begin{tabular}{|c|c|c|c|c|c|c|c|c|}
\hline \multirow[t]{2}{*}{$\begin{array}{l}\text { Variáveis } \\
\text { Variables }\end{array}$} & \multicolumn{5}{|c|}{$\begin{array}{c}\text { Níveis de concentrado (\%) } \\
\text { Concentratelevels } \\
\end{array}$} & \multirow[t]{2}{*}{ ER } & \multirow[t]{2}{*}{$\mathrm{R}^{2} / \mathrm{r}^{2}$} & \multirow[t]{2}{*}{$\begin{array}{l}\mathrm{CV} \\
(\%)\end{array}$} \\
\hline & 25,0 & 37,5 & 50,0 & 62,5 & 75,0 & & & \\
\hline $\mathrm{kgMS} / \mathrm{dia}(D M I)$ & 7,85 & 8,05 & 8,03 & 7,68 & 7,30 & 1 & 0,97 & 7,32 \\
\hline$\% \mathrm{PV}(\% L W)$ & 1,96 & 2,00 & 1,97 & 1,86 & 1,78 & 2 & 0,93 & 5,78 \\
\hline $\mathrm{gMS} / \mathrm{kg}^{0,75}\left(\mathrm{gDM} / \mathrm{kg}{ }^{75}\right)$ & 87,75 & 89,74 & 88,57 & 84,12 & 80,24 & 3 & 0,94 & 5,95 \\
\hline $\mathrm{CFDN}(N D F I)$ & 1,22 & 1,10 & 0,92 & 0,71 & 0,52 & 4 & 0,99 & 6,60 \\
\hline $\mathrm{CA}(F / G)$ & 10,01 & 8,70 & 7,34 & 6,39 & 6,67 & $\hat{Y}=11,4195-0,07189 * * X$ & 0,84 & 24,86 \\
\hline $\mathrm{DC}(D F)$ & 195,62 & 173,75 & 157,12 & 145,25 & 149,50 & $\hat{Y}=212,55-0,966^{* *} X$ & 0,80 & 16,45 \\
\hline
\end{tabular}

1: $\hat{Y}=6,88+0,05634 n s X-0,000680001^{* * *} X^{2}$

2: $\hat{Y}=1,79725+0,0106485 n s X-0,000146286^{*} X^{2}$

3: $\hat{Y}=79,3192+0,521691 \mathrm{~ns} X-0,006868^{*} X^{2}$

4: $\hat{Y}=1,61875-0,01443^{\star *} X$

${ }^{* *},{ }^{*} \mathrm{e}^{* * *}$ Significativo a 1,5 e $10 \%$ de probabilidade pelo teste $" \mathrm{t} "{ }^{* *},{ }^{*}$ and ${ }^{* * *}$ Significant at $[P<.01],[P<.05]$ and $[P<.10]$ by $" t "$ test $)$.

trado. Resposta quadrática também foi verificada por ARAÚJO et al. (1997), TIBO et al. (1997) e OLIVEIRA et al. (1998).

Os consumos em relação ao peso vivo (\%PV) e por unidade de tamanho metabólico $(\mathrm{g} / \mathrm{kg} 0,75)$ também responderam de forma quadrática $(\mathrm{P}<0,05)$ à inclusão de concentrado nas rações, estimando-se consumos máximos de 1,99\% PV e 89,22 gMS/ $/ \mathrm{kg}^{0,75}$, para os níveis de 36,71 e $37,96 \%$ de concentrado, respectivamente. Resposta quadrática também foi verificada por TIBO et al. (1997), para o consumo expresso em g/ $/ \mathrm{kg}^{0,75}$, discordando, porém, de OLIVEIRA et al. (1998), que não observaram efeito da inclusão de concentrado na ração, quando se ajustou o consumo em função do peso metabólico $\left(\mathrm{g} / \mathrm{kg}^{0,75}\right)$.

Respostas curvilíneas para os consumos foram também verificadas por VEIRA et al. (1994). Por outro lado, FERREIRA (1997) averiguou aumento linear nesta variável, para todas as suas formas de expressão.

Os consumos de FDN obtidos em relação ao peso vivo tiveram resposta linear decrescente, em função dos níveis de concentrado nas rações. Na medida em que se elevaram os níveis de concentrado, a regulação foi atribuída a fatores metabólicos e quimiostáticos (BALCH e CAMPLING, 1962). À semelhança deste trabalho, CARVALHO et al. (1996), ao fornecerem dietas com teores de 20 a $70 \%$ de concentrado e feno de capim-elefante (Penisetum Purpureum Schum.) para animais Nelore, também encontraram redução do consumo de FDN.
Dessa forma, acredita-se que o consumo de forrageiras tropicais pode estar correlacionado com a capacidade do trato digestivo dos animais e, portanto, teores elevados de volumoso nas dietas podem provocar o enchimento do rúmen, limitando o consumo.

$\mathrm{O}$ valor de $1,22 \% \mathrm{PV}$, para o consumo de FDN, encontrado neste estudo, com o nível de $25 \%$ de concentrado na ração, foi inferior a 1,31\% PV, relatado por RODRIGUEZ et al. (1996), para o mesmo nível de concentrado. Nesse aspecto, é possível que parte das variações, para os resultados encontrados na literatura, seja atribuída a diferenças na natureza das dietas, como a qualidade do volumoso utilizado.

A conversão alimentar decresceu linearmente ( $\mathrm{P}<0,01)$, com o aumento dos níveis de concentrado nas rações (Tabela 2). Vários trabalhos demonstraram efeito semelhante (GONÇALVES et al., 1991; EUCLIDES FILHO et al., 1997; e FERREIRA, 1997). Os valores para conversão alimentar encontrados neste estudo foram inferiores aos relatados por OLIVEIRA et al. (1998), nos tratamentos de 37,5; 50,0; e 62,5\% de concentrado para Nelore, e aos observados por FERREIRA (1997), nos tratamentos de 25,0;37,5;50,0; e 62,5\% de concentrado, para animais F1 Simental x Nelore. Segundo NEUMANN (1977), maior densidade energética resulta em maior ingestão de energia; assim, menos alimento é requerido para o ganho de peso.

A influência dos níveis de concentrado nas rações foi observada também sobre o tempo (dias) de 
GESUALDI JR. et al.

confinamento (Tabela 2), apresentando resposta linear decrescente $(\mathrm{P}<0,01)$. Os animais que receberam nível de concentrado mais alto chegaram ao peso de abate primeiro, quando comparado com os animais que receberam menores teores de concentrado, demonstrando maior eficiência do sistema. O resultado encontrado foi similar ao verificado por FERREIRA (1997) e OLIVEIRA et al. (1998).

Os consumos de proteína bruta (CPB), em g/dia, e nutrientes digestíveis totais (CNDT), em kg, calculados considerando os valores médios de consumo de MS de cada um dos 10 tratamentos, conforme a Tabela 2, são apresentados na Tabela 3, na qual se compararam os dois sistemas de balanceamento.

Foi observado que o CNDT esteve na faixa de 4,0 a $5,57 \mathrm{~kg} /$ dia, permitindo ganhos entre $0,800 \mathrm{e} 1,200 \mathrm{~kg} / \mathrm{dia}$ (Tabela 4). No entanto, segundo o NRC (1984), para estes ganhos, animais semelhantes aos utilizados neste estudo precisariam de ingestão em torno de
6,02 a $6,44 \mathrm{~kg} / \mathrm{dia}$.

Já os CPB estiveram próximos aos valores de 0,798 a $0,890 \mathrm{~kg} / \mathrm{dia}$, preditos pelo NRC (1984), para ganhos na faixa de 0,800 a $1,200 \mathrm{~kg} / \mathrm{dia}$, para touros de tamanho médio, pesando $400 \mathrm{~kg}$ de peso vivo. Este intervalo de ganho é semelhante ao encontrado neste estudo, para animais do mesmo tipo, conforme a Tabela 4.

Segundo o NRC (1984), quantidades de proteína maiores que as especificadas nas tabelas deste trabalho podem aumentar o desempenho animal no início do período de alimentação, mas animais consumindo menores quantidades de proteína terão ganhos compensatórios mais tarde.

Apesar da necessidade de sincronização entre a degradação de carboidratos e proteínas, para adequado uso da proteína degradada no rúmen (NRC, 1996), nível 2, conforme proposta do CNCPS, bovinos de corte em confinamento parecem representar

Tabela 3 - Consumos de proteína bruta (CPB), em g/dia, e nutrientes digestíveis totais (CNDT), em kg/dia, para as rações balanceadas segundo o NRC (1996) e o NRC (1984)

Table 3 - Crude protein intake (CPI), in g/day, and total digestive nutrients intake(TDNI), in kg/day, for the NRC (1996) and NRC (1984) diets

\begin{tabular}{llccccc}
\hline & \multicolumn{5}{c}{ Níveis de concentrado } \\
& & \multicolumn{5}{c}{ Concentrate levels } \\
\cline { 2 - 7 } NRC (1996) & $\begin{array}{l}\text { CPB (g/dia) } \\
\text { (CPI, g/day) }\end{array}$ & 834 & 951 & 1028 & 1105 & 1131 \\
CNDT(kg/dia) & 4,01 & 4,51 & 4,72 & 5,13 & 5,31 \\
NRC (1984) & $\begin{array}{l}\text { (TDNI, kg/day) } \\
\text { CPB (g/dia) } \\
(\text { CPI, g/day) }\end{array}$ & 834 & 850 & 882 & 864 & 896 \\
& $\begin{array}{l}\text { CNDT(kg/dia) } \\
(\text { TDNI, kg/day) }\end{array}$ & 4,38 & 4,79 & 5,39 & 5,14 & 5,57 \\
\hline
\end{tabular}

Tabela 4 - Médias e equações de regressão (ER), com os respectivos coeficientes de determinação e variação, para os ganhos médios diários de pesos vivos (GMDPV) e vazio (GMDPVZ) e ganho de carcaça (GCAR), em função dos níveis de concentrado $(X)$ nas rações, \%

Table 4 - Means and fitted regressions, with the coefficients of variation and determination, for the daily live weight (LW), empty body (EBW) and carcass gain (CG), in function of concentrate levels in the diets, \%

\begin{tabular}{|c|c|c|c|c|c|c|c|c|}
\hline \multirow[t]{2}{*}{$\begin{array}{l}\text { Variáveis } \\
\text { Variables }\end{array}$} & \multicolumn{5}{|c|}{$\begin{array}{c}\text { Níveis de concentrado (\%) } \\
\text { Concentrate levels }\end{array}$} & \multirow[t]{2}{*}{$\mathrm{ER}$} & \multirow[t]{2}{*}{$\mathrm{R}^{2} / \mathrm{r}^{2}$} & \multirow[t]{2}{*}{$\begin{array}{l}\mathrm{CV} \\
(\%)\end{array}$} \\
\hline & 25,0 & 37,5 & 50,0 & 62,5 & 75,0 & & & \\
\hline$\overline{\operatorname{GMD}(L W)}$ & 0,85 & 1,03 & 1,11 & 1,19 & 1,10 & 1 & 0,94 & 16,97 \\
\hline $\operatorname{GMDPVZ}(E B W)$ & 0,79 & 0,95 & 1,12 & 1,28 & 1,24 & $\hat{Y}=0,592+0,00981 * * X$ & 0,87 & 19,28 \\
\hline $\operatorname{GCAR}(C G)$ & 0,54 & 0,66 & 0,77 & 0,84 & 0,78 & 3 & 0,95 & 13,56 \\
\hline
\end{tabular}

1: $\hat{Y}=0,252498+0,0299444^{*} X-0,000245143^{\star} X^{2}$

3: $\hat{Y}=0,0702501+0,02321^{* *} X-0,00018^{* \star} X^{2}$

${ }^{* *} \mathrm{e}$ * Significativo a 1 e $5 \%$ de probabilidade pelo teste "t" (** and * Significant at $[P<.01]$ and $[P<.05]$ by "t" test. 
1464 Rev. bras. zootec.

uma categoria menos exigente. Por outro lado, o baixo consumo de NDT pelos animais, observado neste trabalho, pode ter reduzido o patamar de ganho de peso vivo, reduzindo a necessidade de elevação de proteína da dieta.

À medida que avança o período de confinamento, substituindo-se a fase de crescimento pela fase de terminação, a necessidade de proteína dos bovinos reduz. Nesse aspecto, a composição do ganho de peso vivo começa a favorecer a deposição de gordura corporal (PAULINO, 1996).

Este estudo concorda com os resultados de SALOMONI et al. (1980) que utilizaram níveis crescentes de energia na terminação de novilhos azebuados, recebendo rações isoprotéicas, não encontrando diferenças estatísticas no ganho médio diário de peso vivo. ALVES et al. (1998), também, não relataram diferenças nos consumos de matéria seca, na conversão alimentar e no ganho médio diário de peso vivo, ao fornecerem duas dietas com silagem de milho a novilhos Zebu e mestiços, mesmo verificando diferenças na ingestão de proteína bruta, da ordem de $0,270 \mathrm{~kg} / \mathrm{dia}$, entre as dietas.

HENNING et al. (1993), trabalhando com ovelhas, concluíram que, ao melhorar o grau de sincronização entre as taxas de liberação de energia e nitrogênio no rúmen, não houve aumento na produção microbiana.

Estudos mostram, ainda, que os bovinos podem compensar a falta de sincronização entre a disponibilidade de energia e proteína, aumentando o número de refeições por dia, como ocorre em confinamento (NRC, 1996)

$\mathrm{Na}$ Tabela 4, são apresentadas as médias e as equações ajustadas, com os respectivos coeficientes de determinação e variação, para os ganhos médios diários de peso vivo e vazio e ganho de carcaça, expressos em quilograma, em função dos diferentes níveis de concentrado nas rações, expressos em porcentagem.

A inclusão de concentrado nas rações teve efeito quadrático nos ganhos médios diários de peso vivo $(\mathrm{P}<0,05)$ (Figura 2$)$ e de carcaça $(\mathrm{P}<0,01)$ e linear nos ganhos médios diários de peso corporal vazio $(\mathrm{P}<0,01)$. Estimaram-se ganhos médios diários de peso vivo e carcaça máximos de 1,16 e $0,81 \mathrm{~kg}$, a partir de 61,11 e $64,47 \%$ de concentrado, respectivamente.

Segundo os estudos de VEIRA et al. (1994), ARAÚJO et al. (1997) e TIBO et al. (1997), a resposta animal à adição de concentrado nas rações é curvilínea e não-linear. Já os resultados encontrados para ganho médio diário de peso corporal vazio

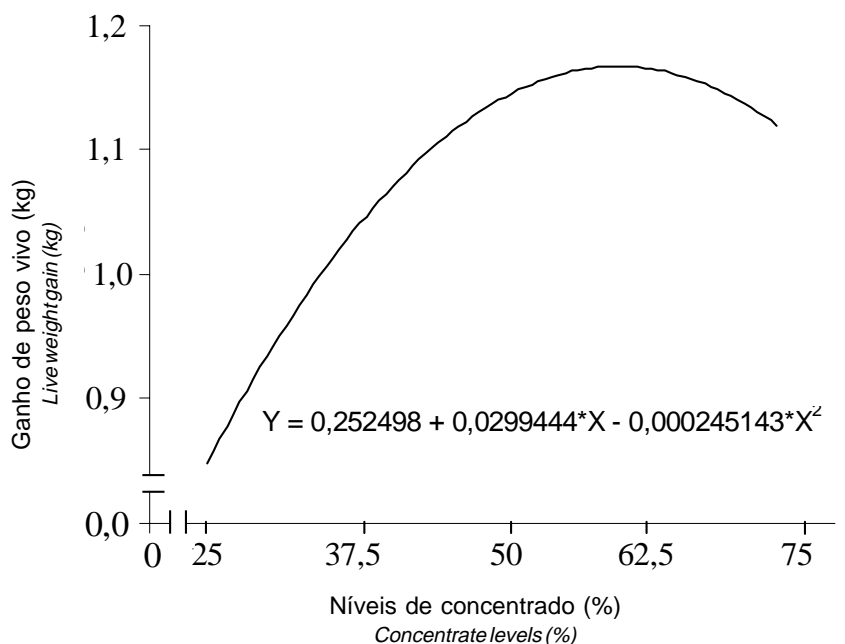

Figura 2 - Estimativa do ganho médio diário de peso vivo (GMD), expresso em kg, em função dos níveis de concentrado nas rações $(X)$, expressos em porcentagem.

Figure 2 - Estimates of live weight gain (LWG), in $\mathrm{kg}$, in function of concentrate levels, expressed in percentage.

concordam com os de FERREIRA (1997) e OLIVEIRA et al. (1998), os quais obtiveram aumento dos valores, a partir do incremento de concentrado nas dietas.

Os ganhos médios diários de peso vivo e peso corporal vazio para os valores de 50,0;62,5; e 75\% de concentrado, encontrados neste trabalho, foram inferiores aos reportados por OLIVEIRA et al. (1998), que utilizaram relações volumoso/concentrado semelhantes.

O ganho médio diário de carcaça reflete a eficiência do sistema para obter o produto a ser comercializado - a carcaça. Os valores encontrados de 0,77 e $0,84 \mathrm{~kg}$, para os níveis de 50,0 e $62,5 \%$ de concentrado respectivamente, mostraram-se semelhantes aos relatados por JORGE et al. (1997), ao fornecerem dietas com relação volumoso/concentrado de 50/50, para animais bimestiços e meio sangue Holandês x Nelore, 0,80 e $0,83 \mathrm{~kg}$, respectivamente.

As variações observadas entre experimentos, no comportamento de animais de diferentes raças e graus de sangue, resultaram de diferenças no nível nutricional e no manejo (GALVÃO et al., 1991; RODRIGUEZ et al., 1996). Além disso, respostas aos tratamentos podem ser influenciadas pelo padrão genético dos animais, o que resulta nas diferenças de porte e desempenho, tanto entre raças quanto dentro 
Tabela 5 - Consumos estimados de matéria seca, nas formas de feno (CMSF) e concentrado (CMSC), expressos em kg, ganho total de arrobas (GTAR) e custo total por arroba (CTA), de acordo com os níveis de concentrado nas rações (\%)

Table 5 - Estimates of dry matter intake, as hay (HDMI) and concentrates (CDMI), in kg, total gain in arrobas (@TG) and total costs for arroba (@TC), in function of concentrate levels in the diets (\%)

\begin{tabular}{lrrrrr}
\hline \multirow{2}{*}{$\begin{array}{l}\text { Variáveis } \\
\text { Variables }\end{array}$} & \multicolumn{5}{c}{ Níveis de concentrado } \\
& \multicolumn{5}{c}{ Concentrate levels } \\
\cline { 2 - 6 } & \multicolumn{1}{c}{5,0} & \multicolumn{1}{c}{50,0} & \multicolumn{1}{c}{62,5} & \multicolumn{1}{c}{75,0} \\
\hline CMSF (HDMI) & 1144,67 & 868,24 & 623,81 & 416,73 & 270,73 \\
CMSC (CDMI) & 383,06 & 520,94 & 623,81 & 694,54 & 812,20 \\
GTAR(@TG) & 7,00 & 7,66 & 8,03 & 8,09 & 7,69 \\
CTA1(U\$)(@TC1) & 38,09 & 31,86 & 27,29 & 24,08 & 24,56 \\
CTA2(U\$)(@TC2) & 41,26 & 35,85 & 31,83 & 29,09 & 30,70 \\
\hline
\end{tabular}

CTA1: preço do feno - 0,15U $\$ / \mathrm{kg}$ e preço do concentrado - 0,15U $\$ / \mathrm{kg}$.

CTA2: preço do feno - 0,15U $\$ / \mathrm{kg}$ e preço do concentrado - 0,20U $\$ / \mathrm{kg}$.

@TC1: hay cost $-.15 \cup \$ / \mathrm{kg}$ and concentrate cost $-.15 \cup \$ / \mathrm{kg}$.

@TC2: hay cost $-.15 U \$ / \mathrm{kg}$ and concentrate cost $-.20 U \$ / \mathrm{kg}$.

da própria raça e grau de sangue.

$\mathrm{Na}$ Tabela 5, são apresentados os consumos de matéria seca, nas formas de feno (CMSF) e concentrado (CMSC), o ganho total de arrobas (GTAR) e o custo total por arroba (CTAR), para os animais de cada tratamento, durante todo o período de confinamento. Realizaram-se duas simulações, levando-se em conta diferentes preços de mercado para feno e concentrado.

É possível concluir que, a partir de custos viáveis de volumoso e concentrado e havendo remuneração por uma carcaça de melhor qualidade, o sistema de alimentação que utiliza maior nível de concentrado tende a se tornar mais eficiente, à medida que se reduz o tempo gasto em confinamento e os custos de produção, visto que a maior parte destes custos é decorrente da alimentação.

\section{Conclusões}

Os consumos de matéria seca responderam de forma quadrática, mostrando que o nível em torno de $50 \%$ de concentrado, na ração de animais cruzados, pode limitar o consumo, devido à densidade energética. A conversão alimentar e o tempo de confinamento (dias) foram menores, com maiores níveis de concentrado nas dietas.

Os ganhos médios diários de peso vivo e carcaça responderam de forma quadrática, apresentando os valores máximos de 1,16 e $0,81 \mathrm{~kg}$, para os níveis de 61,11 e $64,47 \%$ de concentrado, respectivamente, enquanto o ganho de peso corporal vazio cresceu linearmente com o aumento do nível de concentrado na dieta.

A forma de balanceamento das rações não alte- rou os parâmetros estudados. O baixo consumo de NDT pelos animais pode ter diminuído o potencial para ganho de peso vivo, reduzindo a necessidade de elevação de proteína da dieta.

O nível de $62,5 \%$ de concentrado resultou no menor custo total da arroba, porque reduziu ao máximo o tempo de confinamento dos animais.

\section{Referências Bibliográficas}

ALVES, J.B., STAGLIANO, R.L., BASTOS, J.F.P. et al. Desempenho de novilhos zebuínos e mestiços em confinamento com diferentes alimentações. In: REUNIÃO ANUAL DA SOCIEDADE BRASILEIRA DE ZOOTECNIA, 35, 1998, Botucatu. Anais... Botucatu: SBZ, 1998, p.311.

ARAÚJO, G.G.L, COELHO DA SILVA, J.F., VALADARES FILHO, S.C. et al. Consumo e digestibilidade total dos nutrientes de dietas contendo diferentes níveis de volumoso, em bezerros. In: REUNIÃO ANUAL DA SOCIEDADE BRASILEIRA DE ZOOTECNIA, 34, 1997, Juiz de Fora. Anais... Juiz de Fora: SBZ, 1997, p. 234.

BALCH, G.C., CAMPLING, R.C. 1962. Regulation of voluntary intake in ruminants. Nutr. Abstr. Ver., 32:669-686.

BARTLE, S.J., PRESTON, R.L., MILLER, M.F. 1994. Dietary energy sources and density: effects of roughage equivalent, tallow level, and steers type on feedlot performance and carcass characteristics. J. Anim. Sci., 72(8):1943-1953.

BURGER, P.J., PEREIRA, J.C., COELHO DA SILVA, J.F. et al. Consumo e digestibilidade em bezerros alimentados com dietas contendo níveis de concentrado. In: REUNIÃO ANUAL DA SOCIEDADE BRASILEIRA DE ZOOTECNIA, 35, 1998, Botucatu. Anais... Botucatu: SBZ, 1998, p. 599.

CARVALHO, A.U., VALADARES FILHO, S.C., COELHO DA SILVA, J.F. et al. Efeito de níveis de concentrado sobre o consumo e digestibilidade aparente em zebuínos. In: REUNIÃO ANUAL DA SOCIEDADE BRASILEIRA DE ZOOTECNIA, 33, 1996, Fortaleza. Anais... Fortaleza: SBZ, 1996, p.61.

EUCLIDES FILHO, K., EUCLIDES, V.P.B., FIGUEIREDO, G.R. et al. 1997. Avaliação dos animais Nelore e seus mestiços com Charolês, Fleckvieh e Chianina, em três dietas. 1. Ganho de 
1466 Rev. bras. zootec.

peso e conversão alimentar. R. Bras. Zootec., 26(1):66-72.

EUCLIDES FILHO, K., FIGUEIREDO, G.R., EUCLIDES, V.P.B. et al. Conversão alimentar e ganho de peso de animais nelore F1 Simental-Nelore e Angus-Nelore, In: REUNIÃO ANUAL DA SOCIEDADE BRASILEIRA DE ZOOTECNIA, 33, 1996, Fortaleza. Anais... Fortaleza: SBZ, 1996, p.67.

FEIJÓ, G.L.G., SILVA, J.M., THIAGO, L.R.L. et al. Efeito de níveis de concentrado na engorda de bovinos confinados. Desempenho de novilhos F1 Pardo Suíço x Nelore. In: REUNIÃO ANUAL DA SOCIEDADE BRASILEIRA DE ZOOTECNIA, 33, 1996, Fortaleza. Anais... Fortaleza: SBZ, 1996, p.70.

FERREIRA, M.A. Desempenho, exigências nutricionais e eficiência de utilização de energia metabolizável para ganho de peso de bovinos F1 Simental x Nelore. Viçosa, MG: UFV, 1997. 97p. Tese (Doutorado em Zootecnia) - Universidade Federal de Viçosa, 1997.

GALVÃO, J.G., FONTES, C.A.A., PIRES, C.C. et al. 1991. Ganho de peso, consumo e conversão alimentar em bovinos não-castrados, de três grupos raciais, abatidos em diferentes estádios de maturidade (estudo I). R. Soc. Bras. Zootec., 20(5):494-501.

GONÇALVES, L.C., SILVA, J.F.C., ESTEVÃO, M.M. et al. 1991. Consumo e digestibilidade da matéria seca e da energia em zebuínos e taurinos, seus mestiços e bubalinos. R. Bras. Zootec., 20(4):384-395.

HENNING, P.H., STEYN D.G., MEISSNER, H.H. 1993. Effect of synchronization of energy and nitrogen supply on ruminal characteristics and microbial growth. J. Anim. Sci., 71:2516-2528.

JORGE, A.M., FONTES, C.A.A., FREITAS, J.A. et al. 1997. Ganho de peso e de carcaça, consumo e conversão alimentar de bovinos e bubalinos, abatidos em dois estádios de maturidade. R. Bras. Zootec., 26(4):806-812.

LADEIRA, M.M., VALADARES FILHO, S.C., COELHO DA SILVA, J.F. et al. Dietas contendo diferentes níveis de concentrado em novilhos Nelore: consumo e digestibilidade aparente total. In: REUNIÃO ANUAL DA SOCIEDADE BRASILEIRA DEZOOTECNIA, 35, 1998, Botucatu. Anais... Botucatu: SBZ, 1998, p.576.

MERTENS, D.R. Análise da fibra e sua utilização na avaliação e formulação de rações. In: SIMPÓSIO INTERNACIONAL DE RUMINANTES, 29, 1992, Lavras. Anais... Lavras: SBZ, 1992, p.188.
MERTENS, D.R. 1994. Regulation of forage intake. In: FAHEY, G.C., COLLINS, M., MERTENS, D.R., MOSER, L.E. (Eds) Forage quality evaluation and utilization. Madison: ASA. CSSA, SSSA. p.450-493.

NATIONAL RESEARCH COUNCIL - NRC. 1984. Nutrients requeriments of beef cattle. 6.ed. Washington, D.C. 90p.

NATIONAL RESEARCH COUNCIL - NRC. 1987. Predicting feed intake offood producing animal. Washington, D.C. 92p.

NATIONAL RESEARCH COUNCIL - NRC. 1996. Nutrients requeriments of beef cattle. 7.ed. Washington, D.C. $244 \mathrm{p}$.

NEUMANN, A.L. 1977. Beef cattle. University of Illinois. 883p.

OLIVEIRA, S.R., COELHO DA SILVA, J.F., VALADARES FILHO, S.C. et al. Desempenho de novilhos Nelore, não castrados, recebendo rações com vários níveis de concentrado. In: REUNIÃO ANUAL DA SOCIEDADE BRASILEIRA DE ZOOTECNIA, 35, 1998, Botucatu. Anais... Botucatu: SBZ, 1998, p.155.

PAULINO, M.F. Composição corporal e exigências nutricionais de energia, proteina e macroelementos minerais $(\mathrm{Ca}, \mathrm{P}, \mathrm{Mg}$, Na e K) de bovinos não-castrados de quatro raças zebuínas em confinamento. Viçosa, MG: UFV, 1996. 80p. Tese (Doutorado em Zootecnia) - Universidade Federal de Viçosa, 1996

PETIT, H.V., VEIRA, D.M., YU, Y. 1994. Growth and carcass characteristics of beef steers fed silage and different levels of energy with or without protein supplementation. J. Anim. Sci., 72(6):3221-3229.

RODRIGUEZ, L.R.R., FONTES, C.A.A., JORGE A.M. et al. 1996. Consumo de rações contendo quatro níveis de concentrado por bovinos holandeses e nelores e por bubalinos. R. Soc. Bras. Zootec., 25(3):568-575.

SALOMONI, E., TIESENHAUSEN, I.M.E.V., PEREIRA, E.A Níveis de energia na terminação de novilhos "azebuados" em confinamento. In: REUNIÃO ANUAL DA SOCIEDADE BRASILEIRA DE ZOOTECNIA, 17, 1980, Fortaleza. Anais... Fortaleza: SBZ, 1980, p.43.

Recebido em: 23/11/99

Aceito em: 20/03/00 